\title{
A Novel Mutation (S54C) of the PAX8 Gene in a Family with Congenital Hypothyroidism and a High Proportion of Affected Individuals
}

\author{
Panudda Srichomkwun $^{a}$ Osnat Admoni ${ }^{c}$ Samuel Refetoff ${ }^{a}$ b Liat de Vries $^{d, e}$ \\ ${ }^{a}$ Department of Medicine and ${ }^{b}$ Department of Pediatrics and the Committee on Genetics, The University of \\ Chicago, Chicago, III., USA; 'Pediatric Endocrine Unit, Ha'Emek Medical Center, Afula, ' Institute for Endocrinology \\ and Diabetes, Schneider Children's Medical Center of Israel, Petach Tikva, and 'Sackler Faculty of Medicine, \\ Tel Aviv University, Tel Aviv, Israel
}

\section{Established Facts}

- $\quad P A X 8$ gene mutations are one of the genetic causes of thyroid dysgenesis.

- To date, 22 different $P A X 8$ gene mutations have been reported in humans.

\section{Novel Insights}

- Identification of a novel single nucleotide substitution (c.162 A>T) in the PAX8 gene that resulted in the replacement of the normal serine 54 with a cysteine (S54C) in a large family with variable magnitude of hypothyroidism and with a high proportion of affected individuals.

\section{Key Words}

Genetic endocrine disorder · Hypothyroidism · Novel mutation · Thyroid hemiagenesis · PAX 8 - Thyroid

\footnotetext{
Abstract

Background: Congenital hypothyroidism $(\mathrm{CH})$ is a common endocrine disorder in newborns. The cause of $\mathrm{CH}$ is thyroid dysgenesis in $80-85 \%$ of patients. Paired box gene 8 (PAX8) is a thyroid transcription factor that plays an important role in thyroid organogenesis and development. To date, 22 different PAX8 gene mutations have been reported. Methods: Four generations of a Hungarian Jewish family were affected, and in the 3 generations studied, 9 males and 4 females
}

were affected and 3 first-degree relatives were unaffected. Six were diagnosed at birth [thyroid-stimulating hormone (TSH) level $59-442 \mathrm{mU} / \mathrm{l}$ ] and 7 at $2-48$ years of age (TSH level 6-223 mU/l). One affected patient had thyroid hemiagenesis on ultrasound. Results: Direct sequencing of the PAX8 gene revealed a novel single nucleotide substitution (c.162 A>T) in exon 2 that resulted in the substitution of the normal serine 54 with a cysteine (S54C), which segregated with elevated serum TSH levels. Other mutations of the same amino acid (S54G and S54R) have also been shown to produce functional impairment. Conclusion: We report a large family with a novel mutation in the PAX8 gene presenting with variable phenotype and with a high proportion of affected family members.

(c) 2016 S. Karger AG, Basel

\section{KARGER}

(c) 2016 S. Karger AG, Basel

E-Mail karger@karger.com

www.karger.com/hrp
Liat de Vries, MD

Sackler Faculty of Medicine, Tel Aviv University

Ramat Aviv, PO Box 39040

Tel Aviv 69978 (Israel)

E-Mail liatd@ clalit.org.il 


\section{Introduction}

Congenital hypothyroidism (CH; OMIM: 218700) is a common endocrine disorder in newborns with an incidence of $1: 4,000$ to $1: 1,500$, depending on the assigned cutoff thyroid-stimulating hormone (TSH) value $[1,2]$. In $80-85 \%$ of cases, $\mathrm{CH}$ is secondary to thyroid dysgenesis, which presents with a thyroid gland that may be absent (athyreosis), hypoplastic (hypoplasia), or located in an unusual position (ectopy). In the remaining $15-20 \%$ of cases, $\mathrm{CH}$ results from inborn errors of thyroid hormone biosynthesis, secretion, or recycling (dyshormonogenesis) [3]. Thyroid dysgenesis occurs mostly as a sporadic disease; however, a genetic cause has been demonstrated in about $5 \%$ of the reported cases. To date, mutations in genes involved in thyroid organogenesis have been identified in the following genes: thyroid transcription factors 1 and 2 (TTF1 or NKX2.1 and TTF2 or FOXE1), NK2 homeobox 5 (NKX2.5), thyrotropin receptor (TSHR), transcription factor GLI similar 3 (GLIS3), and the paired box gene 8 (PAX8) [4] [PAX8 OMIM: 167415]. The latter, a paired domain-containing protein belonging to the Pax family of transcription factors, is expressed in the thyroid gland, kidney, and central nervous system [5]. The PAX8 gene is located on human chromosome 2q12-q14 and consists of 11 exons encoding a 128 -amino-acid protein, which plays an important role in thyroid organogenesis [4]. In the adult thyroid, PAX8 is an essential regulator of thyroid-specific gene expression such as thyroid peroxidase (TPO), thyroglobulin (TG), and sodium/iodide symporter (NIS) [6]. PAX8 gene mutations are inherited in an autosomal dominant fashion [4], which contrasts with the recessive inheritance in Pax8 knockout mice [7]. To date, 22 different $P A X 8$ gene mutations have been reported in humans $[4,8]$. Systematic $P A X 8$ gene mutation screening was performed in 17 cohorts of patients with $\mathrm{CH}$. Mutations occurred with a prevalence of $1.0 \%$, ranging from 0 to $3.4 \%[8,9]$. The clinical phenotype of individuals with identical $P A X 8$ gene mutations can be variable, ranging from overt $\mathrm{CH}$ with severe thyroid hypoplasia to subclinical $\mathrm{CH}$ with a morphologically normal gland. The majority of $P A X 8$ gene mutations are located within the DNAbinding paired domain and result in a severe reduction in DNA-binding affinity [3].

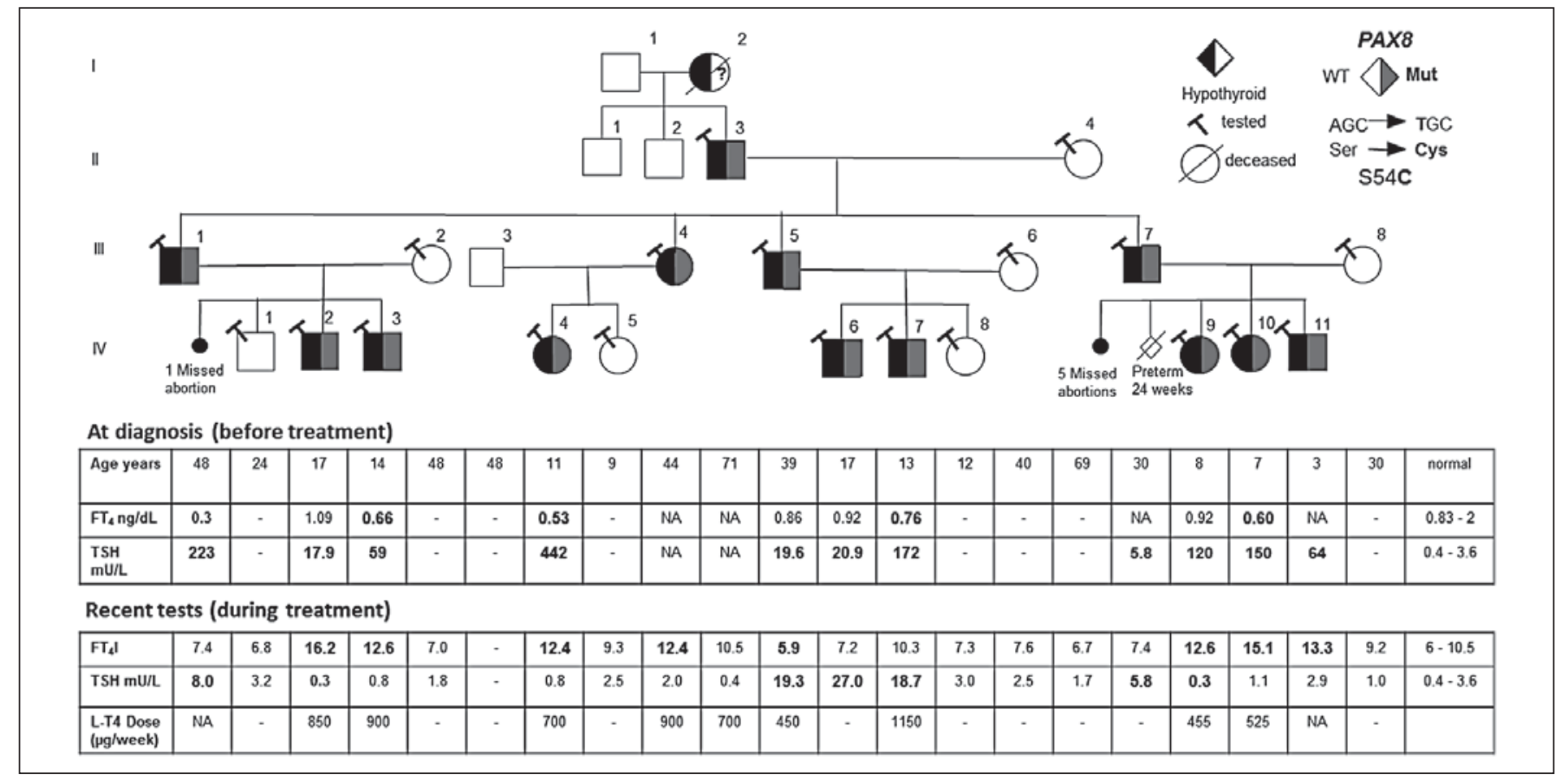

Fig. 1. Pedigree of the family and results of the thyroid function test before and after treatment. Round and square symbols denote females and males, respectively. Each generation corresponds to a Roman numeral. Arabic numerals above each symbol identify the subjects. Laboratory data are aligned below each symbol. Abnormal values are given in bold. Filled and open symbols denote hypothyroid and euthyroid subjects, respectively. Gray symbols de- note the presence of a heterozygous $P A X 8$ gene mutation. The question mark in the symbol of subject I-2 indicates that while she likely carried the PAX8 gene mutation, this was not confirmed as she was deceased at the time the genetic study was undertaken. $\mathrm{FT}_{4}=$ Free $\mathrm{T}_{4} ; \mathrm{NA}=$ not assessed; $\mathrm{FT}_{4} \mathrm{I}=$ free $\mathrm{T}_{4}$ index $; \mathrm{L}-\mathrm{T} 4=\mathrm{le}$ vothyroxine. 


\section{Patients and Methods}

\section{Case History}

Four generations of a Jewish family of Hungarian origin were affected. Of the three generations studied, 9 males and 4 females were affected and 3 were unaffected first-degree relatives (fig. 1). Of the 6 miscarriages, 5 occurred in 1 woman (III-8). Clinical features of all family members are shown in table 1 . Affected individuals had hypothyroidism of variable severity diagnosed at different ages. None of them had autoantibodies to thyroperoxidase or thyroglobulin. Six (patient IV-3, IV-4, IV-6, IV-9, IV-10, and IV-11) were diagnosed at birth with TSH values ranging from 59 to $442 \mathrm{mU} / \mathrm{l}$. The remaining 7 affected individuals were diagnosed at 2-48 years of age, with serum TSH values from 6 to $223 \mathrm{mU} / \mathrm{l}$. Note that in Israel the screening program for $\mathrm{CH}$ is based on the measurement of total $\mathrm{T}_{4}\left(\mathrm{TT}_{4}\right)$ followed by a confirmatory TSH test on samples with $\mathrm{T}_{4}$ values below the 10th percentile. Thus, it is possible that individuals with $\mathrm{T}_{4}$ within the normal range (for example IV-7) were missed in the neonatal screening. Of note is a striking variability in the initial clinical presentation within the family. For example, in the first nuclear family, patient IV-3 was identified by neonatal screening while his affected brother (IV-2) had a normal TSH value upon neonatal screening and was found to have subclinical hypothyroidism at the age of 6 years. His father (III-1) was found to have overt hypothyroidism at the age of 48 years when he was admitted to hospital for severe weakness. He also showed Parkinson's and chronic kidney disease of unknown cause with normal renal ultrasound. Renal function tests (serum urea and creatinine) were normal in all affected individuals. Ultrasound of the kidney in 4 other affected family members (IV-6, IV7 , IV-10, and II-3) was normal. In the second nuclear family, patient IV-4 was found to be hypothyroid following neonatal study, while her mother was diagnosed at the age of 14 years after presenting with delayed puberty. No test results prior to treatment could be found. In the third nuclear family, patient IV-6 was found to be hypothyroid following neonatal screening while his younger brother (IV-7) was diagnosed at the age of 3 years with a very high TSH level. His father (III-5) was found to have high TSH values in adulthood, after presenting with dizziness without hypothyroidism-related manifestations. In the fourth nuclear family, patient IV-9 was found to have $\mathrm{CH}$ with thyroid hemiagenesis, while in her brother (IV-11), hypothyroidism was diagnosed at the age of 3 years. He had normal thyroid gland imaging, and his father (III7) had asymptomatic subclinical hypothyroidism identified only while testing for the present study. Six affected individuals had neurologic and cognitive abnormalities, developmental delay, and/or attention deficit hyperactive disorder.

\section{Thyroid Function Tests}

Blood was collected locally and shipped for analysis to the Chicago laboratory. $\mathrm{TSH}, \mathrm{TT}_{4}$ and $\mathrm{TT}_{3}$ were measured on the Elecsys Automated System (Roche Molecular Biochemicals GmbH and Hitachi, Ltd., Indianapolis, Ind., USA) platform, total reverse $\mathrm{T}_{3}$ by ZenTech (Liege, Belgium), TG by in-house radioimmunoassay,

Table 1. Clinical and genetic characteristics of the examined family members

\begin{tabular}{|c|c|c|c|c|c|c|c|c|c|c|}
\hline $\begin{array}{l}\text { Family } \\
\text { member }\end{array}$ & $\begin{array}{l}\text { Mutation } \\
\text { carrier }\end{array}$ & Gender & $\begin{array}{l}\text { Age, } \\
\text { years }\end{array}$ & $\begin{array}{l}\text { Age at } \\
\text { diagnosis, } \\
\text { years }\end{array}$ & $\begin{array}{l}\text { TSH level at } \\
\text { diagnosis }{ }^{\mathrm{a}} \text {, } \\
\mathrm{mU} / \mathrm{l}\end{array}$ & $\begin{array}{l}\text { Free } \mathrm{T}_{4} \text { at } \\
\text { diagnosis }{ }^{\mathrm{b}} \text {, } \\
\text { ng/dl }\end{array}$ & Thyroid imaging & $\begin{array}{l}\text { Current } \\
\text { height, } \\
\mathrm{cm} \text { (SD) }\end{array}$ & $\begin{array}{l}\text { Current } \\
\text { L-T4 dose, } \\
\mu \mathrm{g} / \text { week }\end{array}$ & Comorbidity \\
\hline II-3 & yes & M & 71 & NA & NA & NA & $\begin{array}{l}\text { normal position, } \\
\text { texture and size }\end{array}$ & $171.5^{\mathrm{e}}(-0.8)$ & 700 & - \\
\hline II-4 & no & $\mathrm{F}$ & 69 & - & - & - & - & NA & - & - \\
\hline III-1 & yes & M & 48 & 48 & 223 & $<0.3$ & NA & $166^{\mathrm{e}}(-1.6)$ & unknown dose & $\mathrm{CKD}, \mathrm{PD}$ \\
\hline III-2 & no & $\mathrm{F}$ & 48 & - & - & - & - & $152^{\mathrm{e}}(-1.5)$ & - & - \\
\hline III-4 & yes & $\mathrm{F}$ & 44 & 14 & NA & NA & NA & $162^{\mathrm{e}}(-0.05)$ & 900 & - \\
\hline III-5 & yes & M & 39 & 30 & 19.6 & 0.86 & NA & $169.8^{\mathrm{e}}(-0.8)$ & 450 & - \\
\hline III-6 & no & $\mathrm{F}$ & 40 & - & - & - & - & $167.5^{\mathrm{e}}(0.65)$ & - & - \\
\hline III-7 & yes & M & 30 & 30 & 5.8 & - & NA & $178^{\mathrm{e}}(0.5)$ & - & - \\
\hline III-8 & no & $\mathrm{F}$ & 30 & - & - & - & - & $152^{\mathrm{e}}(-1.5)$ & - & - \\
\hline IV -1 & no & M & 24 & - & - & - & - & $171^{\mathrm{e}}(-0.7)$ & - & - \\
\hline IV -2 & yes & M & 17 & 6 & 17.9 & 1.09 & NA & $167.2(-1.15)$ & 850 & - \\
\hline IV -3 & yes & M & 14 & NS & 59 & 0.66 & NA & $147(-1.96)$ & 900 & ADHD IGHD \\
\hline IV -4 & yes & $\mathrm{F}$ & 11 & NS & 442 & 0.53 & $\begin{array}{l}\text { normal position, } \\
\text { normal texture }^{c}\end{array}$ & $135.3(-1.31)$ & 700 & $\mathrm{DD}$ \\
\hline IV -5 & no & $\mathrm{F}$ & 9 & - & - & - & - & $135(0.097)$ & - & ADHD \\
\hline IV-6 & yes & M & 17 & NS & 20.9 & 0.92 & hypoechoic, normal position $^{c}$ & NA & - & LD \\
\hline IV -7 & yes & $\mathrm{M}$ & 13 & 3 & 172 & 0.76 & normal thyroid scan ${ }^{\mathrm{d}}$ & $154(-0.55)$ & 1,150 & ADHD \\
\hline IV -8 & No & $\mathrm{F}$ & 12 & - & - & - & - & $153(0.41)$ & - & ADHD \\
\hline IV -9 & yes & $\mathrm{F}$ & 8 & NS & 120 & 0.92 & thyroid hemiagenesis ${ }^{c}$ & $120(-2.08)$ & 455 & - \\
\hline IV -10 & yes & $\mathrm{F}$ & 7 & NS & 150 & 0.60 & normal thyroid scan ${ }^{\mathrm{d}}$ & $115(-1.44)$ & 525 & - \\
\hline IV-11 & yes & M & 3 & NS & 64 & NA & normal thyroid scan ${ }^{\mathrm{d}}$ & $86(-1.65)$ & unknown dose & $\mathrm{DD}$ \\
\hline
\end{tabular}

Abnormal values are given in bold. $\mathrm{SD}=$ Standard deviation; $\mathrm{L}-\mathrm{T} 4=$ levothyroxine; $\mathrm{NA}=$ not available; $\mathrm{CKD}=$ chronic kidney disease; $\mathrm{PD}=\mathrm{Parkinson}$ 's disease; NS = newborn screening; ADHD = attention deficit hyperactive disorder; IGHD = idiopathic growth hormone deficiency; DD = developmental delay; $\mathrm{LD}=$ learning disorder. ${ }^{\mathrm{a}}$ Normal range of TSH value: adult $0.4-3.6 \mathrm{mU} / \mathrm{l}$, at birth $<20 \mathrm{mU} / \mathrm{l}$; ${ }^{\mathrm{b}}$ normal range of free $\mathrm{T}_{4}$ : adult $0.83-2 \mathrm{ng} / \mathrm{dl}$, at birth $0.93-1.48 \mathrm{mg} / \mathrm{dl} ;{ }^{\mathrm{c}}$ ultrasound thyroid; ${ }^{\mathrm{d}}$ technetium scan; ${ }^{\mathrm{e}}$ final height. 
Fig. 2. a Chromatograms showing sequences for normal (WT/WT) and heterozygote (Mut/WT); the square box is covering the region of the mutation. b Alignment of the Pax8 amino acid sequence encoded by exon 2 and containing the mutant Ser54 in various species, including mammals, amphibians, and fish. Amino acid differences are given in bold letters. a



WT/WT

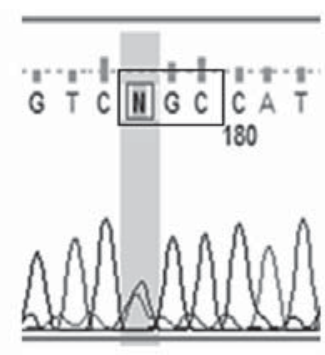

Mut/WT b

PAX8 exon 2 (residues 9-64)

HUMAN GHGGLNQLGGAFVNGRPLPEVVRQRIVDLAHQGVRPCDISRQLRVSHGCVSKILGR CHIMPANZEE GHGGLNQLGGAFVNGRPLPEVVRQRIVDLAHQGVRPCDIS RQLRVSHGCVSKILGR DOG GHGGLNQLGGAFVNGRPLPEVVRQRIVDLAHQGVRPCDIS RQLRVSHGCVSKILGR

RAT GHGGLNQLGGAFVNGRPLPEVVRQRIVDLAHQGVRPCDIS RQLRVSHGCVSKILGR

MOUSE GHGGLNQLGGAFVNGRPLPEVVRQRIVDLAHQGVRPCDIS RQLRVSHGCVSKILGR XENOPUS GHGGLNQLGGAFVNGRPLPEVVRQRIVDLAHQGVRPCDIS RQLRVSHGCVSKILGS ZEBRAFISH GHGGLNQLGGMFVNGRPLPEVIRQRIVDMAHQGVRPCDIS RQLRVSHGCVSKILGR

\section{Ser54}

and antibodies to TG and TPO by the Kronus (Star, Idaho, USA). The free $\mathrm{T}_{4}$ index was calculated from the $\mathrm{TT}_{4}$ and the resin $\mathrm{T}_{4}$ uptake ratio.

\section{DNA Analysis}

The clinical and genetic studies were approved by the institutional review boards. After written informed consent was obtained from all participating family members, genomic DNA from peripheral mononuclear blood cells was isolated using the QIAamp DNA Mini Kit (Qiagen) followed by amplification of genomic DNA by polymerase chain reaction and direct sequencing of the $P A X 8$ gene, exons 0 through exon 11. All polymerase chain reaction samples were sequenced using automated fluorescence-based sequencing (3730XL 96 capillary; Applied Biosystem Carlsbad, Calif., USA). Primer sequences are available upon request.

\section{Results}

Direct sequencing of exon $0-11$ of the $P A X 8$ gene revealed a novel single nucleotide substitution in exon 2 of the PAX8 gene (c.162 A>T) that resulted in the substitution of the normal serine 54 with a cysteine (S54C) (fig. 2a). This S54C mutation cosegregated with a biochemical hypothyroid phenotype in all three generations tested (fig. 1). Evaluation of the new sequence alterations using 'PolyPhen-2' indicated that this variant is 'probably damaging', with a score of 0.997 .

\section{Discussion}

We identified a novel mutation in the PAX8 gene, present in all 13 affected individuals of the family. The thyroid phenotype was considerably variable, with respect to (1) thyroid function (overt to subclinical hypothyroidism), (2) onset of disease (at birth to late adulthood), and (3) thyroid gland anatomy (hemiagenesis to normal). Variable phenotypic expression in PAX8 mutations has been reported in several families. Patients can be euthyroid or severely hypothyroid, and the thyroid development can range from athyreosis to normal-sized orthotropic gland $[4,10-16]$. Possible explanations for interfamilial variability include a polygenic etiology, epigenetic mechanisms that cause stochastic variations of gene expression at multiple loci, variation in the timing of PAX8 expression in embryonic life, or somatic mutations with a dominant effect in a thyroid development gene [17].

The S54C Pax8 mutation affects a highly conserved amino acid in the paired domain which lies between the second and the third helical region of the N-terminal homeodomain-like motif (fig. 2b). Other mutations of the same amino acid (S54G and S54R) have also been shown to exhibit functional impairment. Meeus et al. [18] identified an S54G mutation in a French family with $\mathrm{CH}$. In addition, one of the affected siblings displayed unilateral 
kidney disease. Functional analysis of the mutant PAX8 demonstrated that it is unable to bind a specific cis-acting element of the promoter and has almost lost the ability to control together with TTF1 TG gene transcription. Hermanns et al. [19] reported an S54R mutation in 2 members of a Turkish family. In vitro studies showed that the mutant protein had an impaired binding to the TPO and $T G$ gene promoter-binding sites and exerted a dominant negative effect on the wild-type PAX8. Both reports support a functional impairment of a mutant amino acid at this location.

The $P A X 8$ gene is expressed in the kidney and plays an important role in its development. Urogenital malformations (horseshoe kidney, undescended testes, hydrocele, ureterocele, and kidney agenesis) associated with $P A X 8$ gene mutations have been previously reported [18, 20]. One of the affected individuals of this family had chronic kidney disease, but kidney ultrasound showed no abnormal urogenital malformation. Four other affected members of the family were found to have normal kidney ultrasounds. Interestingly, 6 affected members of the family had neurologic or cognitive abnormalities including Parkinsonism, developmental delay, and attention deficit hyperactive disorder. This suggests a possible association between the PAX8 gene mutation and neurocognitive impairment, which has not been previously reported. The PAX8 gene is transiently expressed during development in the myencephalon and in the entire length of the neural tube, but no expression is detected in the brain at later stages or in adults [5]. Its role in these tissues has not been as well demonstrated as in the kidney and thyroid, and no neurological dysfunction is evidenced in Pax8 knockout mice [7]. Thus, it is currently not possible to determine whether the neurological manifestations could be attributed to the mutation. In this respect, it should be noted that 2 of the 4 family members with attention deficit hyperactive disorder did not carry the PAX8 gene mutation (IV-5 and IV-8). Another unusual feature is the high proportion of individuals harboring the mutation (13 of 16) when in autosomal dominant inheritance one would have expected an equal number of affected and unaffected cases.

In conclusion, we report a large family with a novel PAX8 gene mutation (S54C) causing autosomal dominant $\mathrm{CH}$ of variable expressivity and with a high proportion of affected individuals.

\section{Acknowledgements}

This work is supported in part by grant R37DK15070 from the National Institutes of Health and the Seymour J. Abrams fund for thyroid research (to S.R.). We thank all family members for their participation in this study. We are grateful to the following colleagues for advice in the course of investigation: Dr. Roy E. Weiss, Dr. Alexandra M. Dumitrescu, and Dr. Theodora Pappa.

\section{Disclosure Statement}

The authors declare that they have no conflicts of interest.

\section{References}

1 Dattani M, Brook CG: Outcomes of neonatal screening for congenital hypothyroidism. Curr Opin Pediatr 1996;8:389-395.

-2 Corbetta C, Weber G, Cortinovis F, Calebiro D, Passoni A, Vigone MC, Beck-Peccoz P, Chiumello G, Persani L: A 7-year experience with low blood TSH cutoff levels for neonatal screening reveals an unsuspected frequency of congenital hypothyroidism $(\mathrm{CH})$. Clin Endocrinol 2009;71:739-745.

-3 Nettore IC, Cacace V, De Fusco C, Colao A, Macchia PE: The molecular causes of thyroid dysgenesis: a systematic review. J Endocrinol Invest 2013;36:654-664.

4 Pohlenz J, Van Vliet G, Deladoëy J: Developmental abnormalities of the thyroid; in Weiss RE, Refetoff S (eds): Genetic Diagnosis of En- docrine Disorders. London, Academic Press, 2016, pp 127-136.

5 De Felice M, Di Lauro R: Thyroid development and its disorders: genetics and molecular mechanisms. Endocr Rev 2004;25:722-746.

6 6 Marotta P, Amendola E, Scarfo M, De Luca P, Zoppoli P, Amoresano A, De Felice M, Di Lauro R: The paired box transcription factor Pax8 is essential for function and survival of adult thyroid cells. Mol Cell Endocrinol 2014; 396:26-36.

7 Mansouri A, Chowdhury K, Gruss P: Follicular cells of the thyroid gland require $P A X 8$ gene function. Nat Genet 1998;19:87-90.

$\checkmark 8 \mathrm{Fu}$ C, Chen R, Zhang S, Luo S, Wang J, Chen Y, Zheng H, Su J, Hu X, Fan X, Luo J, Yi S, Lai Y, Li C, Xie B, Shen Y, Gu X, Chen S: Pax8 pathogenic variants in Chinese patients with congenital hypothyroidism. Clin Chim Acta 2015;450:322-326.

-9 Szinnai G: Genetics of normal and abnormal thyroid development in humans. Best Pract Res Clin Endocrinol Metab 2014;28:133-150.

10 de Sanctis L, Corrias A, Romagnolo D, Di Palma T, Biava A, Borgarello G, Gianino P, Silvestro $L$, Zannini $M$, Dianzani I: Familial PAX8 small deletion (c.989_992delaccc) associated with extreme phenotype variability. J Clin Endocrinol Metab 2004;89:5669-5674.

11 Hermanns $\mathrm{P}$, Grasberger H, Refetoff S, Pohlenz J: Mutations in the NKX2.5 gene and the $P A X 8$ promoter in a girl with thyroid dysgenesis. J Clin Endocrinol Metab 2011; 96:E977-E981. 
12 Narumi S, Araki S, Hori N, Muroya K, Yamamoto Y, Asakura Y, Adachi M, Hasegawa T: Functional characterization of four novel $P A X 8$ mutations causing congenital hypothyroidism: new evidence for haploinsufficiency as a disease mechanism. Eur J Endocrinol 2012;167:625-632.

13 Macchia PE, Lapi P, Krude H, Pirro MT, Missero C, Chiovato L, Souabni A, Baserga M, Tassi V, Pinchera A, Fenzi G, Grüters A, Busslinger M, Di Lauro R: PAX8 mutations associated with congenital hypothyroidism caused by thyroid dysgenesis. Nat Genet 1998; 19:83-86.

14 Ramos HE, Carre A, Chevrier L, Szinnai G, Tron E, Cerqueira TL, Leger J, Cabrol S, Puel O, Queinnec C, De Roux N, Guillot L, Castanet M, Polak M: Extreme phenotypic variability of thyroid dysgenesis in six new cases of congenital hypothyroidism due to $P A X 8$ gene loss-of-function mutations. Eur J Endocrinol 2014;171:499-507.

15 Bereket A LX, Turoglu T, Aribal E, Refetoff S: Analysis of the PAX8 gene in congenital hypothyroidism caused by different forms of thyroid dysgenesis in a father and daughter. J Pediatr Endocrinol Metab 2004;17:10211029.

16 Congdon T, Nguyen LQ, Nogueira CR, Habiby RL, Medeiros-Neto G, Kopp P: A novel mutation (q40p) in PAX8 associated with congenital hypothyroidism and thyroid hypoplasia: evidence for phenotypic variability in mother and child. J Clin Endocrinol Metab 2001;86:3962-3967.

17 Fagman H, Nilsson M: Morphogenetics of early thyroid development. J Mol Endocrinol 2011;46:R33-R42.

18 Meeus L, Gilbert B, Rydlewski C, Parma J, Roussie AL, Abramowicz M, Vilain C, Chris- tophe D, Costagliola S, Vassart G: Characterization of a novel loss of function mutation of $P A X 8$ in a familial case of congenital hypothyroidism with in-place, normal-sized thyroid. J Clin Endocrinol Metab 2004;89:42854291.

19 Hermanns P, Shepherd S, Mansor M, Schulga J, Jones J, Donaldson M, Pohlenz J: A new mutation in the promoter region of the $P A X 8$ gene causes true congenital hypothyroidism with thyroid hypoplasia in a girl with Down's syndrome. Thyroid 2014;24: 939-944.

20 Carvalho A, Hermanns P, Rodrigues AL, Sousa I, Anselmo J, Bikker H, Cabral R, PereiraDuarte C, Mota-Vieira L, Pohlenz J: A new PAX8 mutation causing congenital hypothyroidism in three generations of a family is associated with abnormalities in the urogenital tract. Thyroid 2013;23:1074-1078. 